\title{
CIENCIA POLÍTICA Y SERVICIOS SOCIALES. DEL ENTENDIMIENTO AL CONCUBINAGE
}

\author{
ALFREDO HIDALGO LAVIÉ \\ Doctor en Ciencias Políticas. Profesor de Servicios Sociales y Política Social. E.U.A. de \\ Trabajo Social de Jerez de la Frontera. Universidad de Cádiz.
}

\section{INTRODUCCIÓN}

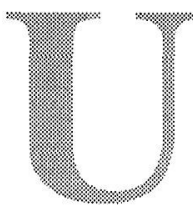

n título de estas características sin considerar al Estado de Bienestar como el epicentro de la obra no es muy corriente, sin embargo, no deja de ser una invitación bienvenida y, en lo que a mí respecta, un desafío seductor inevitable, por lo que agradezco enormemente a la dirección de esta publicación su atención al permitirme colaborar en estas páginas a modo de defensor del diablo en la unión de dos disciplinas que tantos aspectos comunes comparten y, no obstante, no suelen manifestar más abierta y frecuentemente sus confluencias.

Como politólogo, estoy en la obligación de decir que usualmente "lo político", además de la 'mala prensa' que hoy día parece tener esta expresión, no posee coloquialmente precisos contornos conceptuales, por esta razón, la primera tarea en una colaboración de estas características transcurre necesariamente, en primera instancia, por una aproximación conceptual que canalice todo el análisis posterior.

La Ciencia Política es una ciencia más en el seno de las Ciencias Sociales y, como tal, comparte un común punto de partida: el estudio del hombre como ser social, aunque, obviamente, focalizando su objeto en los procesos y conflictos relacionados con la autoridad y el poder que se desenvuelven dentro del mundo o realidad social. Como tal ciencia social, claro está, la apropiación de un ámbito exclusivamente autónomo es cuestionable, por lo que la necesidad de un enfoque inter y pluridisciplinar, la suma de sus resultados con los obtenidos por las otras ramas del saber social, se convierte en condición sine qua non para aspirar a constituirse en ciencia y de este modo ofrecer al conocimiento científico una comprensión racional y objetiva del ámbito de la realidad objeto del análisis. El binomio sujeto/objeto introduce serios problemas epistemológicos que van a determinar no sólo la utili- 
zación de ciertos procedimientos metodológicos, sino que además van a marcar también su finalidad como conocimiento científico. Todas estas consideraciones relevantes van a ser tratadas en la primera parte de esta exposición bajo el rótulo "la Política como Ciencia".

Realizada esta rápida endoscopia sobre los aspectos que más interesa conocer de la Ciencia Política en general, pasaré a presentar las confluencias que, a mi entender, comparten ambas disciplinas, las cuales servirán a su vez de 'rampa de lanzamiento' idónea desde la que subrayar las aportaciones sobresalientes que la Ciencia Política puede ofrecer para un conocimiento más exhaustivo de los Servicios Sociales, haciendo un especial hincapié en la unidad de análisis, por excelencia, de estas dos áreas del saber científico, el individuo-ciudadano.

Por último, he considerado necesario incluir una breve reflexión sobre una referencia que merece toda nuestra atención dada la actualidad y la curiosidad que hoy despierta, la necesidad de un nuevo estilo de hacer democracia, sin ningún interés mayor que el de trazar unas someras líneas a favor de nuestro modelo representativo sin que por ello se entienda, necesariamente, que nuestro sistema democrático, sostenido sobre la delegación, no requiere las suficientes reformas pertinentes para acercar, en la medida de lo posible, el poder político a los ciudadanos.

\section{LA POLÍTICA COMO CIENCIA}

\subsection{La idea de "lo político"}

Conocido es por todos el axioma aristotélico "el hombre es un zoon politikon", pero esta idea incipiente de "lo político" no describe conceptualmente, en absoluto, esta realidad. El animal político de Aristóteles, lejos de lo que puede parecer a simple vista, no es una descripción de la política, sino una concepción explícita de la vida, el modo helénico de entender la realidad vital del ser humano en el seno de la polis, donde la vida política no es una faceta más del quehacer humano, ni siquiera la más primordial, sino su esencia misma, vinculada estrechamente a la comunidad política primitiva. Tendrán que transcurrir bastante siglos para que la noción de lo político quede circunscrita a la esfera del poder, concepto siamés que, entendido en sentido lato, da forma y contenido a la idea común de esta realidad intangible que se manifiesta a través de actos y decisiones de naturaleza política. Este amplio paréntesis en el tiempo ha originado que la idea de lo político haya rodado de modelos sociales y de producción tan diferentes, con matices y acepciones tan diversas, que la locución acabó adop- 
tando incluso significados religiosos con los que deleitar a cualesquiera de las divinidades del hemisferio existencial. No es exagerada, pues, la apreciación de Eduardo Haro Tecglen (1995) al afirmar que todos los cientos de miles de libros que se han escrito en torno al tema no son siquiera suficientes para encerrar todos los conceptos de la palabra política.

Con Maquiavelo, al fin, la política se separa de los ámbitos moral y religioso, estableciendo su propia esfera autonómica, regida por racionales leyes particulares independientemente de lo éticamente descriptivo y originando, de este modo, una amoral idea de lo político que, como es sabido, no tiene por qué causar necesariamente reprochables comportamientos inmorales, fundamentalmente porque Maquiavelo no era indiferente a los efectos que producen la moral y la religión sobre la comunidad política; $y$, si bien es cierto, que, por un lado, condenaba a las virtudes cristianas, como la humildad, la abnegación y el desprecio de las cosas mundanas que causan, en su opinión, 'servilismo de carácter', por otro lado, como consecuencia de su estima hacia el gobierno liberal y sujeto a las leyes, sancionaba la utilización aleatoria e indiscriminada de medios poco dignos por parte de los gobernantes.

Sin embargo, y a pesar del importante paso realizado en el objeto propio que interesa a la política, es comúnmente aceptado que Maquiavelo no puede ser calificado correctamente de científico, ya que su empirismo procedía más del sentido común y sus indagaciones históricas que de la inducción promotora de elaboraciones teóricas y contrastadas. Hábil en la astucia, ni siquiera llegó a formular una teoría general del absolutismo político, aunque, ciertamente, sí fue el creador de un concepto clave para la Ciencia Política: el Estado.

Un paso más en la separación progresiva de lo moral/religioso de lo estrictamente político y, por ende, en la construcción de una esfera particularmente política de la actividad y pensamiento humanos, lo encontramos en la obra de Juan Bodino, no tanto por su elogiable recomendación política de la tolerancia religiosa, a pesar, paradójicamente, de su extremado fervor, como por extraer casi definitivamente la idea del poder soberano de la teoría del derecho divino.

No obstante, no será hasta 1651 cuando la serie de obras escritas por Thomas Hobbes, entre ellas el conocido Leviatán, colocan a lo político en estrecha relación con un sistema de pensamiento completamente moderno y, por ende, completamente autónomo. Si, con Maquiavelo, el Estado gobernaba aceptando las reglas de la política, con Hobbes el Estado gobierna creándolas. Su individualismo, su materialismo y su procedimiento deductivo y no empírico le condujo a considerar la política como parte de un cuerpo manipulable por el conocimiento científico. 
La autonomía de una esfera de lo político arrastrará más tarde una parcela similar en "lo social" con connotaciones económicas. De la mano de autores como David Ricardo o Adam Smith se fraguó la creencia fundada en que toda sociedad bien dirigida era capaz de regularse a sí misma, delegando en el gobierno sólo un papel de importancia muy limitada. Políticamente, la separación Estado/Sociedad-modelo económico debe ser interpretada como el nacimiento y consolidación de un nuevo pensamiento político caracterizado, fundamentalmente, por la libertad de la segunda frente al abstencionismo del primero. Su correspondiente traducción científica versará sobre una ciencia general de la sociedad en la línea del pensamiento filosófico de Comte. En otras palabras, el libre albedrío de las fuerzas ocultas de "una natural mano rectora" inherente a la sociedad de mercado proporcionará crecimiento económico y bienestar social. La injerencia política es considerada, pues, sinónimo de desorden y parcialidad ${ }^{1}$, de este modo, la autonomía de la sociedad es tal que ella misma puede ser objeto de un campo científico y, así pues, susceptible de normas y procedimientos metodológicos con los cuales descubrir realidades y principios sociales 'objetivos' y, evidentemente, contrastados. A este respecto, George Sabine (1987:519) ha argumentado que, "en cierto sentido, la filosofía de Comte fue una culminación de la especulación social que se había iniciado con la enigmática idea de Rousseau de la Voluntad General, el concepto de la sociedad como un ente colectivo con sus propios caracteres y valores y que supera los fines y voluntades de sus miembros", lo que implica, en gran medida, un apreciable y estimable esfuerzo por conducir los estudios sociales al sendero de la ciencia moderna, más aún, a la aparición de nuevas interrogantes que darán lugar al surgimiento de nuevas áreas de conocimiento como la psicología social y la antropología, entre otras.

La política, concebida, desde una perspectiva liberal, como el arte del buen gobierno que permite llegar a acuerdos entre posturas enfrentadas e intereses diametralmente opuestos gracias al poder compartido y fragmentado, hará frente a una nueva concepción de la misma, si se me permite, más "combativa": la conquista y el ejercicio del poder no permiten procedimiento pacífico alguno, la fuerza impulsora del cam-

No obstante, es preciso recordar que las conclusiones de los estudios realizados por Adam Smith sobre la naturaleza humana y el modelo ideal de comunidad político-económica, será distinto del apuntado por la doctrina liberal al enfatizar los injustos desequilibrios que el modelo de producción causa sobre la distribución de la riqueza. En esta línea, Adam Smith (1978:31) afirmará que "por más egoísta que quiera suponerse al hombre, evidentemente, hay algunos elementos en su naturaleza que lo hacen interesarse en la suerte de los otros, de tal modo que la felicidad de éstos le es necesaria, aunque de ello nada obtenga, a no ser el placer de presenciarla". 
bio social no es la negociación, sino la revolución, dado que la naturaleza del poder no es política. Para el marxismo, las fuerzas que impulsan el desarrollo y el devenir de la historia son económicas. La cultura y los modelos políticos encuentran su razón de ser en el modelo de producción; es la teoría del determinismo económico que, aplicado a lo político, explica el materialismo dialéctico en la línea del pensamiento de Hegel.

El breve pero aberrante y cruel periodo de los totalitarismos fascista y nazi, productos de la profunda desmoralización originada por las consecuencias de la Primera Guerra Mundial, eliminó de lo político un elemento consustancial a su trayectoria, enunciado sólo a grandes rasgos en estas primeras páginas, la inteligencia. Un peligroso intento de retroceso hacia un primitivismo originario que, afortunadamente, y a pesar de sus desagradables secuelas, no ha causado daños irreparables en el paulatino desarrollo de identificar lo político con un poder cuyo ejercicio, sobre unas básicas premisas éticas, pero fundamentales, continúa correspondiéndose con la armonía y el consenso desde los que aprehender un modelo racional de convivencia humana, independientemente de si el análisis es de naturaleza liberal, conservadora, socialdemócrata o comunista. Un modelo de convivencia que tras el hundimiento del imperio ubicado tras los Urales es hoy en día el único paradigma exportable, aunque continuamente perfectible, la democracia.

\subsection{La presunción de Ciencia}

La Ciencias Sociales se han enfrentado desde siempre a problemas metodológicos, por lo que, si tuviéramos que prescindir de un intento de definición más amplio, podríamos comenzar afirmando que toda ciencia, o la Ciencia en sentido genérico, es sólo método con el que y desde el cual ser capaces de formular leyes válidas para todos. Por consiguiente, y a modo de primer enunciado, se podría argüir que no hay ciencia propiamente dicha sin método científico, aunque, evidentemente, éste pueda ser múltiple. Asimismo, y a pesar del lógico énfasis realizado sobre el procedimiento, tampoco un saber científico es tal sin hipótesis y generalizaciones, a través de las cuales formular enunciados verdaderos, independientemente del tiempo y del espacio, que comúnmente denominamos leyes.

En lo que concierne a la política y a la ciencia misma, el punto de arranque para un camino conjunto nos obliga a indagar en los escritos de la epistemología y de la filosofía, del mismo modo que toda teoría al respecto no puede prescindir en absoluto de la idea de ciencia que en cada momento histórico se ha compartido. El primer paso dado en esta línea, como hemos visto, se produce con el proceso de demarcación de 
ciertas esferas, tales como la moral o la economía, en pro de un ámbito propio, aunque difícilmente exclusivo, de lo político. Especial atención merece la separación de la filosofía que hizo posible el surgimiento de una Ciencia Política, en el sentido correcto de la expresión, dado que el método, los objetivos y los criterios del politólogo son diferentes. Un ejemplo ilustrativo de esta diferencia deriva de los procedimientos metodológicos entre los que el politólogo utiliza, en un elevadísimo número de casos, el control histórico y comparado, muy en menor medida el estadístico, ¡y qué decir del experimental!. Precisamente, la imposibilidad de recurrir a este último nos recuerda el difícil inconveniente al que tiene que hacer frente la política en su aspiración a configurarse como saber científico: la imprevisibilidad simbólica del sujeto y del objeto, piedra clave sobre la que Giovanni Sartori (1984) ha afirmado que la causalidad propia de las ciencias naturales no es posible encontrarla en las ciencias sociales, puesto que el hombre escapa al modelo fisicalista de explicación causal.

La imposibilidad de enunciados a modo de "a tal estímulo, tal reacción" vuelve a la política inaprensible, sin olvidar, además, que lo que llamamos generalmente político, como sucede igualmente en toda la realidad social, tampoco posee claros contornos nítidamente delimitados. El poder, como ya ha sido señalado, es intangible, por lo que resulta más oportuno hablar de relaciones de poder o de actos y decisiones concretas de naturaleza política, cuestión que nos trae a colación otro ingrediente imprescindible para toda presunción creativa de conocimiento científico: la formación de conceptos, es decir, la delimitación conceptual de ciertos términos útiles que ha de manejarse con precisión en nuestro campo, en definitiva, la importante tarea de sistematizar el lenguaje. ¿Quién no ha alertado alguna vez la utilización indiscriminada de la locución "Estado", por ejemplo, para hacer referencia a aquellas comunidades políticas organizadas con anterioridad a la Edad Moderna?.

Como ya ha sido apuntado, el proceso histórico de demarcación de un ámbito puramente político en el seno de las Ciencias Sociales ha sido largo, ni siquiera el tratamiento de la constitución de la Ciencias Sociales, con precisión histórica, es fácil de evaluar. La literatura sobre la necesidad de validar los enunciados de la realidad social en general mediante una metodología científica es muy abundante, con ejemplos tan ilustrativos como "la crisis de la conciencia europea" de Paul Hazard. La fragmentación del saber en distintos y separados campos formalizados o institucionalizados, impulsados por un deseo permanente de verificación y especialización (la astrología es reemplazada por la astronomía, por ejemplo) es paulatina, proceso durante el cual destacaron figuras brillantes como Descartes y Bacon que también ilustran la confrontación entre el racionalismo y el empirismo, respectivamente. 
Habrá que esperar, no obstante, a toda una serie de autores como Dilthey o Rickert, conocidos bajo el calificativo de "neokantianos", para distinguir, al fin, entre ciencias naturales y ciencias sociales, los cuales, como es sabido, romperán con la unidad metodológica esgrimida por los positivistas ${ }^{2}$, dada la naturaleza tan diferente del objeto de estudio en cuestión, la realidad social subjetiva. Así pues, realizada la bifurcación del pensamiento científico, la unidad de la ciencia quedará confirmada, no siendo incompatible con aplicaciones metodológicas tan dispares como la utilización de datos cuantitativos y empíricos por un lado, y el uso de información simbólica y significativa por otro. Dicho esto, y una vez ubicado el ámbito de lo político en el seno de las ciencias sociales, la cuestión inevitable a resolver es la siguiente: ¿en qué consiste, en definitiva, la Ciencia Política?.

\subsection{Origen y Objeto de la Ciencia Política}

La institucionalización de la Ciencia Política como disciplina científica es de muy reciente aparición en el seno de lo que venimos llamando ciencias sociales, por más que, ciertamente, muchos autores estiman que el primer enfoque científico-político se encuentra ya en la obra de Maquiavelo. Pero ¿participa el análisis de la realidad políticosocial de Maquiavelo de propuestas y enunciados racionales, resultado de la observación y sometidos a su verificación científica?. Ya hemos visto que no y cuán discutible es el procedimiento por él utilizado.

Una opinión más consensuada merece el análisis de Saint Simon y Fourier, aunque será Tocqueville el artífice de la consolidación de la observación y deducción racional de aquello que hemos llamado político.

En un sentido amplio, el objeto de la Ciencia Política está inexorablemente vinculado a la sociedad, a la colectividad, entendida ésta como un agregado de individuos relacionados entre ellos en torno a la columna vertebral de toda comunidad humana: el poder. Desde la antigüedad, el estudio del poder ha inquietado tanto a pensadores y filósofos que la literatura sobre este punto es prolífica, pero esta preocupación, sin embargo, no ha sido analizada a lo largo de los siglos bajo una misma perspectiva. Por ejemplo, con el surgimiento, expansión y posterior consolidación del cristianismo, el poder, procedente o transmitido por dios, era susceptible del mal o buen uso, pero el proceso paula-

2 El enunciado común de los positivistas, como es sabido, afirmaba que el conocimiento científico era único, pero esta unidad se manifestaba igualmente en los procedimientos utilizados, por lo que las ciencias experimentales y las no experimentales, según este argumento, debían utilizar una análoga metodología. 
tino de secularización experimentado a lo largo y ancho del Renacimiento modificó substancialmente la preocupación por el mismo, hasta el punto que las interrogantes que giraban alrededor del poder ya no respondían tanto al fundamento moral como al conocimiento de la propia naturaleza del poder, lo que supuso, lógicamente, un extraordinario salto cualitativo dada la pretensión científica del estudio, justificando, en cierta medida, la partida de bautismo de lo político como área de conocimiento especializada.

Aunque sobre el objeto de la Ciencia Política existe un consenso generalizado, éste no está exento de perfiles matizados de relevantes consideraciones. Así, por ejemplo, para Javier Pérez Royo (1980), el objeto verdadero de la Ciencia Política es el Estado. Estimando la opinión genérica como la más utilizada, podemos concluir, pues, afirmando que el objeto de la Ciencia Política abarca todos los procesos sociales mediados por las relaciones de poder, pero el estudio de estos procesos deben ser no sólo analizados desde un enfoque descriptivo y explicativo, sino también, interpretativo. ¿Por qué?. Porque la finalidad del conocimiento científico en la esfera política no consiste meramente en entender, no se conforma simplemente con la comprensión del fenómeno del poder, también pretende formular previsiones sobre las consecuencias de la aplicación de ciertas medidas propias de su habitual ejercicio.

Ya en la Teoría Política clásica, de Aristóteles a Tocqueville, encontramos una preocupación próxima, aunque no similar, en torno a la política, concretamente la búsqueda de una forma de gobierno óptima. La ausencia de una finalidad en el conocimiento científico de lo político es, en mi opinión, similar a la avitaminosis, por citar un caso muy actual; esto es, una carencia precisa que no permite el buen funcionamiento de nuestro organismo. Así pues, no existe Ciencia Política sin finalidad y ésta, en términos concretos, implica y se corresponde con una búsqueda permanente, cuya piedra angular y razón de ser consiste en la aprehensión de toda una serie de elementos de juicio que permitan edificar una comunidad humana apta "para todo género de público", una convivencia pacífica que garantice el libre desarrollo de nuestras potencialidades como seres autónomos y propietarios exclusivos de nuestra particular empresa, un proyecto vital. Sin esta expresa finalidad, los conocimientos de nuestro medio serían inocuos.

Nuestra finalidad, similar en su general premisa al conjunto de las áreas que constituyen las Ciencias Sociales, es, por consiguiente, y para concluir, influir sobre la realidad para mejorarla, un proceso circular, ya que el sujeto y el objeto se entremezclan, muy diferente del proceso lineal propio de las ciencias naturales. 


\section{CIENCIA POLÍTICA Y SERVICIOS SOCIALES. UN DENOMI- NADOR COMÚN}

\subsection{La imprescindible necesidad de un enfoque pluridisciplinar.}

La Ciencia Política es considerada normalmente un saber de segundo orden porque versa sobre realidades complejas cuya crucial interpretación exige necesariamente conocimientos de otros saberes, tales como el Derecho, la Historia, la Economía, etc. Es, pues, un saber científico de naturaleza enciclopédica dada su necesidad imprescindible de aplicar un enfoque pluri e interdisciplinar. Este reciente convencimiento, generalizado en toda nuestra comunidad científica, no ha sido siempre fielmente compartido y, por tanto, no exento de perspectivas alternativas con las que construir y cultivar, como apunta Ramón Cotarelo (1986), una Ciencia Política sin el auxilio de otras ramas del conocimiento. Así, del Derecho son utilizados los aspectos normativos, y de la Sociología el interaccionismo simbólico, por ejemplo.

Este requisito multidimensional no debe ser entendido como una "impureza" que imposibilita la construcción y delimitación de un área de conocimiento autónomo. Más aún, la consideración de esta necesidad puede y debe ser interpretada positivamente, pues la fusión de elementos de naturaleza diversa produce una serie de resultados útiles para el enriquecimiento de todas las otras áreas. Numerosos son los ejemplos de esta confluencia, tales como la relación entre la Economía y la Estructura Social, el Derecho Constitucional y los Sistemas Políticos, por citar algunos. Esta línea fronteriza difusa es, en los modelos sociales complejos de la actualidad, más patente aún, dada la globalización de la naturaleza de los problemas acuciantes de nuestro tiempo presente.

Lógicamente, este enfoque pluridisciplinar se configura igualmente como un denominador común entre la Ciencia Política y los Servicios Sociales. No podría ser de otro modo. Por definición, los Servicios Sociales son, en pocas palabras, instrumentos de política social y la política social es ya un ámbito de actuación gubernamental enmarcada en un modelo específico de organización política, el Estado de Bienestar. No es de extrañar, a este respecto, el acertado enunciado de Carmen Alemán (1996:36) al afirmar que "los servicios sociales guardan una estrecha vinculación con la Ciencia Política, y no sólo porque estos servicios se insertan dentro de un contexto político determinado, sino porque, en su propio fundamento, son manifestaciones de decisiones políticas", de lo que puede deducirse, por consiguiente, que todo estudio acerca de los servicios sociales no puede prescindir de la comprensión del móvil y de los resultados de las decisiones y actuaciones 
gubernamentales que, sin duda alguna, corresponde a la Ciencia Política describir, valorar e interpretar. Sobre este punto específico, y como suele decirse coloquialmente, "se puede rizar aún más el rizo" ante la irremediable necesidad de tener en cuenta además: a) el modelo de organización territorial de un Estado; b) el proceso paulatino de construcción de la Unión Europea con la consiguiente coordinación de las políticas sociales que conlleva este proceso; c) el corporatismo, pronunciado o no, característico de los modelos políticos democráticos que conlleva a reconocer un papel también central a los grupos de presión de toda índole en el quehacer cotidiano de las propuestas políticas. La descentralización/centralización territorial, por ejemplo, incrementa o disminuye el número de actores políticos que estarán obligados a coordinar planes y programas, entre otros asuntos. La existencia misma de un sistema público de servicios sociales responde a una concepción específica del rol que debe corresponder al Estado en aras de una finalidad también muy concreta, el bienestar social, recordándonos una vez más esta finalidad el leimotiv de la Ciencia Política: "conocer para mejorar".

Asimismo, el conocimiento de los servicios sociales exige necesariamente tener en cuenta el complejo entramado de interacciones entre actores que deciden o influyen notablemente en el ejercicio de una intervención positiva, negativa o abstencionista, según los modelos establecidos por Demetrio Casado (1991), del protagonista político número uno, para cuya comprensión las aportaciones del análisis sistémico de David Easton, como veremos un poco más adelante, son de gran consideración.

Todas estas observaciones, en torno a las áreas de actuación sobre las que versan, y comparten, los objetos de estudio de los Servicios Sociales y la Ciencia Política, nos conducen, a su vez, e irremediablemente, a otro aspecto científico relevante: la sistematización del lenguaje con la consiguiente delimitación conceptual de las locuciones y voces que tan común y frecuentemente son utilizadas por nuestras disciplinas. Para la Ciencia Política, como para todas las ciencias sociales, es indispensable construir un lenguaje comprensible desde el que utilizar las categorías propias de nuestro objeto de estudio y con el que y para el cual el politólogo describe, analiza, interpreta y predice. Muchas de estas categorías distan mucho de esa difusa línea fronteriza anteriormente señalada, tales como el poder, la autoridad, la obediencia, el conflicto, etc. Pero otras, sin embargo, sí comparten el denominador común de lo que vamos a llamar confluencia conceptual. Por esta razón, las locuciones bienestar social, mercado o democracia desarrollada, entre otras, no pueden ser monopolio ni de la Economía, ni de la Sociología, ni del Trabajo Social. Estas realidades conceptuales, a modo de "espacio aéreo y marítimo internacional", también deben 
tener en cuenta las importantes aportaciones procedentes de la Ciencia Política, dada, fundamentalmente, su vinculación con el poder y el modo de organizarse las comunidades humanas. Una relación interdisciplinaria, en definitiva, que tal y como se ha indicado a comienzos de este apartado, debe ser considerada positiva y sin la cual, según indican Jorge Garcés y Carmen Alemán (1996) en el prólogo de su nueva obra, "no puede prosperar intelectualmente si se basa en fronteras y exclusivismos estériles, sino en el trabajo común y en el esfuerzo solidario".

\subsection{Aportaciones específicas de la Ciencia Política a los Servicios Sociales}

Llegado a este punto, los vínculos que parecían entrelazar tímidamente los Servicios Sociales con la Ciencia Política se tornan ahora más estrechos. El objeto y la finalidad de la Ciencia Política, junto a la también esencial contribución que ésta realiza en la paulatina y cambiante delimitación conceptual de ciertas realidades entrecruzadas y, por ende, ligadas fuertemente a la esfera de los Servicios Sociales, constituyen un sólido puente que refuerza el permanente entendimiento común. No obstante, las aportaciones que la Ciencia Política puede ofertar a la disciplina de los Servicios Sociales no se agotan aquí, por lo que es preciso enumerar otras de similar relevancia que paso a señalar a continuación.

\subsubsection{El concepto de ciudadanía y la participación en asuntos comu- nitarios}

Aquello que entendemos por político utiliza como elemental unidad de análisis, especialmente desde el enfoque característico del individualismo metodológico, al individuo, cuya suma y agregado configura lo colectivo, que da lugar, a su vez, y en última instancia, a toda una comunidad política. Es, por consiguiente, obvio que el sujeto destinatario del elenco de servicios sociales, y el sujeto que participa en el proceso de las relaciones de poder, se configura, ya en principio, en vértice común. Pero, simultánemante, el concepto de ciudadano está estrechamente ligado a los derechos que a éste le corresponden por ser miembro de una comunidad política específica, por lo que su significado no se puede entender sin hacer irremediablemente referencia al origen, naturaleza, protección y consiguiente ejercicio y desarrollo de los mismos.

Sobre este punto, tanto el constitucionalismo moderno como la Ciencia Política han recurrido indistintamente al emblemático momento histórico de las revoluciones burguesas que dan inicio al apasionante 
período de nuestra historia contemporánea. El disparo de salida procede de la proclamación de la Declaración de los Derechos del Hombre y del Ciudadano, aprobada por la Asamblea Nacional francesa en 1789, materializando en su documento escrito la libertad y la igualdad en los derechos de todos los hombres, consagrando una de las más importantes victorias del ciudadano sobre el poder político.

Como es sabido, el resultado feliz de la universal Declaración francesa ha sido de tal magnitud que ha eclipsado otras declaraciones semejantes de también suma importancia política. Así, los Bills of Rights de las colonias americanas, que se sublevaron contra el imperialismo de Inglaterra en 1776, y el Bill of Rights puramente inglés, tras la denominada "Revolución Gloriosa" de 1689, son considerados, sin lugar a dudas, como sus dos principales precedentes. Aunque el matiz ${ }^{3}$ que distingue a los dos primeros del Bill of Rights inglés es relevante, se puede afirmar en ambos casos, y seguir sosteniendo, que el concepto de ciudadanía está vinculado, pues, a toda una serie de derechos que lo delimitan conceptualmente y éstos, a su vez, a un concepción abstracta del individuo, para lo que la Teoría Política cuenta con útiles herramientas de análisis y comprensión. Qué duda cabe, por ejemplo, que la naturaleza humana del individuo abstracto de Thomas Hobbes no se corresponde con la realizada por Rousseau.

La paulatina evolución de este concepto va unida al desarrollo paralelo de otras dos nociones estrechamente ligadas también a la Ciencia Política y a los Servicios Sociales: la libertad y la igualdad, cuya expansión semántica ha redundado en la aparición de una tercera clasificación de los derechos junto a los iniciales derechos civiles y políticos. Estoy haciendo referencia, evidentemente, a los derechos sociales.

Llegado a este punto, estamos listos para realizar, al fin, la siguiente afirmación a modo de primer enunciado concluyente: la extraordinaria contribución que la Ciencia Política puede aportar a la esfera cognitiva de los Servicios Sociales es, en primer término, conceptual y explicativa. En la configuración y establecimiento de todo saber científico es necesario, y más aún en la realidad mutante en la que éste se desenvuelve, la conformación de un marco conceptual apropiado y, dado que el destinatario último de los servicios sociales, más allá de ciertos colectivos o grupos más o menos específicos, es el ciudadano, es admisible considerar que la aportación de la Ciencia y Teoría Políticas a este respecto, es, cuando menos, indispensable. Un requisito que

En el Bill inglés no son reconocidos los derechos del hombre, propio de las elucubraciones del Jusnaturalismo y del Contractualismo característico de la época, sino los derechos tradicionales del ciudadano inglés, cuya fuente de inspiración fue la Common Law. 
no abarca sólo la delimitación conceptual de esta elemental unidad de análisis, sino que debe incluir además una explicación acertada de los porqués que circunscriben la noción política de ciudadano en cada momento histórico.

Un segundo elemento clave estrechamente unido al concepto de ciudadano es el de la participación, también igualmente importante para los Servicios Sociales. Como un racimo de cerezas, los conceptos en las ciencias sociales se entrelazan e interrelacionan complementándose, aportando nuevos espacios conceptuales. Así, toda participación bien entendida inexorablemente se constituye, a su vez, en un elemento primordial de una realidad, la cual, aunque normalmente equívoca y pluriforme, delimita un modelo político central para la Ciencia Políti$\mathrm{ca}$, y en cuyo seno se desenvuelve actualmente el sistema público de servicios sociales, la democracia.

El boom asociativo, el fenómeno actual del voluntariado, las influencias ejercidas por los grupos de presión de toda índole, la mayor o menor intensidad del corporatismo, la canalización de las demandas ciudadanas por medio de los partidos políticos, la paulatina descentralización territorial, orgánica y funcional..., no son objetos que deban ser considerados aleatoriamente, sino medidos y analizados en su justa importancia como fenómenos de dos significados interrelacionados, incluso etimológicamente hablando, la democracia v.s. participación. Asimismo, la huida de la colectividad, las tendencias abstencionistas, el desencanto político generalizado, el inquietante desinterés por lo comunitario..., son manifestaciones patológicas del mal endémico originado por una concepción mal entendida tanto de la participación como de la democracia y las cuales son analizadas por la Sociología Política, explicadas en cierta medida por la Cultura Política, pero cuya comprensión global y formulación de soluciones requiere necesariamente un enfoque politológico. La articulación de la participación, la democratización interna de la administración local, la modernización de los procedimientos burocráticos, las posibilidades sin desarrollar aún de nuestra Constitución, tales como la iniciativa legislativa y el referéndum, ¿acaso no son aspectos relevantes de nuestra presente realidad socio-política aptos para una investigación profunda desde un enfoque necesariamente interdisciplinar, pero, por consiguiente, también irremediablemente politológico?

La participación es un componente de la noción de democracia, pero ésta, incluso sólo aplicando procedimientos indirectos, no puede prescindir de la participación. Como ya he indicado, la Ciencia Política no sólo pretende describir y explicar, sino, además, interpretar, evaluar y predecir. Según Juan Amézaga (1994), no se han concretado ni garantizado suficientemente los mecanismos para la participación. La 
falta de movilización y dinamismo social es un rasgo característico de la presente situación socio-política, una manifestación concreta, entre otras, de un contexto político, social, económico y cultural que reclama una solución. En este punto, la Ciencia Política puede aportar sus amplios conocimientos sobre el proceso político de adopción de decisiones, así como promocionar soluciones en común esfuerzo con los profesionales de las otras ramas involucradas. ¿Cómo canalizar, por ejemplo, la tan "cacareada" participación de los ciudadanos en la gestión de los servicios sociales, especialmente, en el ámbito de la administración local?. El saber de lo político puede y debe contribuir en el encuentro de soluciones, porque su colaboración, dicho sea de paso, una vez más, es indispensable para entender el entramado de interacciones de procedencias diversas que participan de los porqués de una específica decisión política adoptada en un momento dado.

Estaremos de acuerdo que, tal y como han comenzado a concebirse actualmente los servicios sociales, su significado incluye conceptualmente la participación de sus principales protagonistas, los usuarios, pero, por encima de esta consideración, ya relevante, se encuentra un principio más importante, pilar de todo sistema democrático: la participación es necesaria porque sin ella no hay un real ejercicio democrático del poder, por lo que sin participación política y ciudadana los miembros de una comunidad no encuentran el medio indispensable para pasar de su condición como individuo/persona, que ostenta ciertos derechos, a la de auténtico ciudadano.

\subsubsection{La finalidad del Estado en proyección histórica}

Tanto para el Trabajo Social, en general, como para los Servicios Sociales, desde un enfoque más específico, hablar de ciudadano/usuario es hacer mención obligatoriamente a necesidades y modos de satisfacción de las mismas. Es hacer referencia, asimismo, a fines tan compremetedores como la cohesión y bienestar sociales a través de la participación de agentes públicos y/o privados. Y, además, generar expectativas desde las que aprehender modelos comunitarios de convivencia en los que los individuos/ciudadanos puedan desarrollar óptimamente sus potencialidades y capacidades a fin de alcanzar su pleno desarrollo personal. Es, pues, y en definitiva, vincular al ciudadano necesaria y forzosamente con el Estado, porque su naturaleza, recursos, objetivos y más excelsa finalidad son, desde hace centurias, condición de la existencia humana.

Como es generalmente admitido, el Estado es sólo una forma histórica de unidad política, por lo que su especifidad original le vuelve diferente tanto de los modelos precedentes como de cualesquiera otras 
alternativas posibles de futuro, por más que, en sentido amplio, aunque incorrectamente, es utilizado coloquialmente para designar todo modelo de convivencia política, siempre existente, sea ya por la naturaleza sociable del ser humano, según el criterio aristotélico, ya por las inseguridades a las que le arrastra su naturaleza pasional y egoísta, pese a su condición antisocial, según Hobbes, razones que llevan a los individuos aislados hacia el artificio de lo colectivo y comunitario para garantizar su integridad física y su propiedad. Independientemente del criterio utilizado con el que explicar el origen de toda comunidad política en función de una concepción abstracta de la naturaleza humana, la finalidad genérica del Estado, satisfacción de necesidades, nos recuerda, como he pretendido señalar a comienzos de este párrafo, cómo éstas devienen denominador común de un análogo objeto de estudio y preocupación de estas áreas de conocimiento. No en vano, las distintas modalidades de satisfacción de las necesidades que en el área de los Servicios Sociales suelen ser clasificadas como antecedentes históricos, tales como "la ayuda mutua", "el reparto medieval", "la irrupción de la beneficencia", "el pauperismo y la seguridad social" 4 , se corresponden, como no podía ser de otro modo, con un modelo específico de Estado o, más concretamente, con una concepción concreta de la finalidad de la comunidad política y sus inevitables e intrínsecas relaciones de poder, según el período histórico objeto de atención.

Así pues, junto a los fines permanentes o consustanciales del Estado, tales como el mantenimiento de su propia conservación como organización ${ }^{5}$, su permanencia como entidad soberana en el marco internacional y la convivencia pacífica en el seno de su delimitación territorial, encontramos otras finalidades más estimables, estrechamente vinculadas a la relación súbdito/ciudadano-poder político en aras del desarrollo integral de los componentes de ese modelo de comunidades específica. De este modo, durante el Despotismo Ilustrado, por ejemplo, ciertos Estados absolutistas se propusieron hacer de la felicidad de sus súbditos el leimotiv de sus intervenciones políticas, para lo que desarrollaron una extensa actividad administrativa. Para el Estado Liberal, por el contrario, la felicidad es un asunto personal, una cuestión privada reservada a la esfera íntima del individuo a la que el Estado no le está permitido interferir, postulando simultáneamente la libertad como supremo valor de la comunidad política, para lo que será necesario la sujeción del poder político a los contenidos de la ley, garantía de las

4 Sobre este apartado, las referencias bibliográficas son, afortunadamente, copiosas. A modo de sugerencia, ver "Los servicios sociales en perspectiva histórica", Documentación Social, n. ${ }^{\circ} 64$, julio/septiembre, 1986

5 Conviene recordar sobre este punto que el Estado ha sido la primera gran organización, propiamente hablando, después de la Iglesia, su gran fuente de inspiración. 
libertades y derechos individuales. Posteriormente, como todos sabemos, el Estado Social o Estado Distribuidor sumará a la finalidad del Estado Liberal precedente los medios necesarios o "procura existencial" con los que los ciudadanos podrán hacer efectiva la utilización de la libertad para su personal proyecto existencial una vez satisfechas sus perentorias necesidades más elementales. Esta confluencia de procesos diversos para la satisfacción de las necesidades humanas ofrecerá, qué duda cabe, una contextualización más enriquecedora de lo que han sido los servicios sociales en el transcurso de los años.

Sin embargo, la importancia de las posibles aportaciones de la Ciencia Política al conocimiento científico de los Servicios Sociales es hoy día mayor, dado el carácter público de los servicios sociales ofertados actualmente y la finalidad del modelo de Estado, cuestionada por la expansión de los principios clásicos del liberalismo-conservador.

Por un lado, la finalidad del Estado de Bienestar, según Ramón Cotarelo (1986), consiste en garantizar el bienestar social pasando a ser ahora la legitimidad del nuevo modelo de organización política la preocupación estatal por canalizar los conflictos sociales pacíficamente y por intervenir en "toda suerte de relaciones privadas", y, por otro lado, los Servicios Sociales se definen como sistema público para la garantía universal de los derechos sociales "dentro de las nuevas estrategias del bienestar social", en opinión de Gustavo García y José Manuel Ramírez (1992). Esta repetida confluencia dado a) el bienestar social como objeto compartido de estudio; b) "el carácter público" de todo el sistema de servicios sociales y, por ende, procedente de las pertinentes instituciones del poder político, independientemente de su mayor o menor descentralización territorial, orgánica y funcional, y c) la condición de los servicios sociales como instrumentos de política social, nos conducen, nuevamente, al punto de inflexión de este artículo: la naturaleza pluridisciplinar característica de la disciplina de los servicios sociales no es una mera invitación a la Ciencia Política en función de ciertos aspectos comunes, objeto de estudio, e intereses de ambas disciplinas, sino que su colaboración es imprescindible dada la naturaleza política de los mismos servicios sociales, so pena, claro está, de convertir el campo científico de los Servicios Sociales en una simple gestión empresarial de ciertos recursos, según los baremos conocidos de la eficiencia y la utilidad.

La crisis del Estado Benefactor, las consecuencias de la globalización económica mundial y, particularmente, el proceso paulatino, pero aparentemente firme, de integración europea presentan día tras día nuevos desafíos a la permanencia de los servicios sociales y a la continuidad de ciertos contenidos de política social. La colaboración interdisciplinar no tiene por qué sustentarse sólo en suplir la compleja falta de autono- 
mía, también podría ser utilizada para reinventar, conjuntamente, nuevos argumentos que consoliden sólidamente la noción de bienestar social en el futuro.

\section{3:2.3. Elementos de un sistema político y sus interacciones}

Si hemos aceptado con convicción el enunciado ligeramente esbozado en la página anterior, según el cual la red de servicios sociales procede de las pertinentes instancias del poder político, no será difícil admitir ahora que éstos son un componente vertebral y definitorio que da contenido al modelo político que denominamos Welfare State, el cual es, a su vez, un modelo teórico de sistema político, y, por ende, los servicios sociales, independientemente que su materialización práctica evidentemente pueda adoptar diversas y numerosas formas de intensidad, se constituyen, pues, como elemento de un sistema político.

La locución "sistema político", como todas las nociones que pretenden sistematizar el lenguaje de las ciencias sociales en general, es equívoca. Propongo utilizarla según una acepción concreta que hace referencia a la vida política de toda la sociedad, así, todo sistema político puede ser identificado con el conjunto de interacciones sociales e institucionales, las cuales asignan valores a una determinada sociedad.

Como término con implicaciones analíticas específicas fue introducido y conocido popularmente por medio de la obra "El sistema político" de David Easton (1953). Paulatinamente, primero en los Estados Unidos y más tarde en Europa, la expresión "sistema político" ha desplazado a la idea de Estado, el cual proporciona una descripción más acertada y completa del dominio del campo de estudio de la Ciencia Política. Como recordarán, la Teoría de Sistemas en su aplicación a las Ciencias Sociales ha sido criticada desde diversas perspectivas, las cuales acaban confluyendo en un vértice común: no existe una Teoría General de sistemas, sino toda una gran familia de sistemas que constituye un bloque teórico cohesionado.

En cuanto a la Ciencia Política se refiere, un enfoque crítico ya conocido es el introducido por el profesor Cotarelo (1979), según el cual, mientras no se produzca una distinción nítida entre el sistema y el medio, siempre estará ausente un factor fundamental para estructurar una verdadera Teoría de sistemas, porque los poderes públicos cuando actúan sobre los ciudadanos sus efectos no sólo recaen sobre el medio, sino también sobre el propio sistema. Pero, por encima de las acertadas críticas y observaciones realizadas sobre la Teoría de sistemas, es honesto reconocer que este enfoque metodológico ha abierto un amplio sendero en nuestra disciplina con el que contrastar, observar y analizar las materias afines a la Ciencia Política, logrando, ciertamente, un 
amplio reconocimiento colectivo nada desdeñable en pro de su virtuosa utilidad. No en vano, esta mencionada utilidad, junto a su vocación integradora y claridad, ha llevado al mismo profesor Cotarelo a enumerar sus ventajas y a concluir que "no es preciso que el paradigma dé respuestas satisfactorias a todos los problemas que se planteen. Será suficiente si redefine el campo científico, orienta a la investigación y permite el ejercicio práctico de la Ciencia como una actividad de resolver rompecabezas" (Ramón Cotarelo, 1979:98/99).

La noción "sistema político" presupone tres supuestos: 1.- toda sociedad se compone de toda una variedad de sistemas de distinta naturaleza; 2.- el sistema político puede abstraerse o diferenciarse para su estudio de los no políticos ${ }^{6} \mathrm{y}$, más importante aún, 3.- todos los subsistemas y elementos que constituyen una sociedad están en permanente interacción e influyéndose constantemente. Este tercer elemento es absolutamente imprescindible a la hora de demostrar, una vez más, la estrecha vinculación que une los Servicios Sociales con la Ciencia Política.

En primer lugar, y en consonancia con lo ya enunciado en párrafos anteriores, si consideramos que los individuos, como afirma David Easton (1969), que intervienen en esas interacciones, y más concretamente los que actúan en roles políticos, son llamados genéricamente miembros del sistema, los procedimientos que éstos utilizan, incluyendo los indirectos, para intervenir en los procesos que en sentido amplio podemos catalogar con la acepción genérica de "sociales" deben ser, pues, considerados igualmente elementos del sistema. Dicho esto, ¿Cómo no vamos a considerar los servicios sociales como un elemento del sistema de bienestar cuando la contracción v.s. expansión de estos instrumentos de política social dependen, primordialmente, de los sujetos o actores centrales que detentan el poder político?. Y, en segundo lugar, y más importante aún, es el enfoque que hace referencia al complejo entramado que conlleva el proceso de adopción de decisiones políticas e implementación de las mismas. Si seguimos sosteniendo que el bienestar social es una finalidad que nos une en cierta medida, no pudiendo obviar que los profesionales más inmersos en estas áreas

" Obsérvese que en la línea de este procedimiento, aunque ciñéndonos a lo que podríamos denominar puramente "social", Salvador Giner (1996:22) también ha señalado a este respecto, en relación a la dificultad de conocimiento en el proceso sociológico, que mientras que "el economista puede hacer abstracción de ciertas dimensiones de la realidad social... y estudiar al hombre como homo oeconomicus (y) lo mismo puede hacer la ciencia política, y entenderlo como homo politicus... en la concepción de homo sociologicus nos vamos a encontrar con que éste será siempre sujeto simultáneo de diversas redes de interrelaciones y de creencias y valores... y es que la multiplicidad de las dimensiones sociales se hace sentir siempre en el estudio de la sociedad". 
como son los trabajadores sociales, encargados de aplicar las políticas sociales ya diseñadas, también en opinión de Natividad de la Red (1996), proporcionan indicadores y argumentos para cambiar estas políticas; el objeto de estudio de los Servicios Sociales tiene que contar necesariamente con los útiles conocimientos necesarios sobre estas instancias de poder que también influyen en el proceso de adopción de decisiones y confluyen así con otros protagonistas copartícipes de las mismas. De este modo, habrá que tenerse en cuenta, igualmente, el papel que desempeñan ciertas administraciones y organismos políticos y entidades tuteladas, así como aquellas entidades que canalizan las demandas sociales, como los partidos políticos y los grupos de presión, cuya naturaleza diversa incluye desde las tradicionales organizaciones sindicales y empresariales hasta la propia comunidad de vecinos en una administración local.

Este complicado compendio de interacciones exige un conocimiento más global y completo de la ya compleja realidad socio-política, lo que justifica, a mi entender, las oportunas observaciones que desde la Ciencia Política se puede aportar al campo y a los contenidos más específicos de los Servicios Sociales.

Una cuestión última a añadir, aunque brevemente expuesta en un par de líneas y cuya brevedad, admito, no se corresponde en absoluto con la crucial importancia que ésta tiene: ¿cómo va a prescindir la disciplina de los Servicios Sociales de las convicciones políticas, del protagonismo subyacente que desempeñan las ideologías, expresamente en estos tiempos de "crisis" del Estado de Bienestar, cuando son éstas las que pueden poner en situación de "jaque-mate" la persistencia misma de la naturaleza pública de todo el conjunto del sistema de servicios sociales??

\section{IV.LA NECESIDAD DE UN NUEVO ESTILO DE HACER DEMO- CRACIA}

Tras la caída del muro de Berlín y la rápida sucesión de acontecimientos que han superado las barreras de todas las previsiones imaginables, la democracia parece disfrutar de un aura de legitimidad, desconocida hasta hace relativamente poco, cimentando, más sólida-

7 Para aquellos 'escépticos' que se han forjado el convencimiento de que los contenidos de las políticas sociales no tienen nada que ver con las orientaciones ideológicas de las fuerzas políticas, es recomendable seguir difundiendo los acertados y oportunos argumentos que Norberto Bobbio (Derecha e Izquierda, Taurus, Madrid, 1995) recoge en su reciente libro sobre las razones y significados que aún, "en los tiempos que corren", dan contenido a una distinción política. 
mente aún, su universal criterio paradigmático exportable a todos los confines del planeta.

Sin embargo, simultáneamente, el descontento, la apatía y un cada vez mayor número de voces críticas manifiestan abiertamente, de diversas formas, su descontento hacia este modelo de organización política, exhibiendo aquellos aspectos que consideran puramente formales de la misma o al menos políticamente poco desarrollados, especialmente en todo lo que respecta a la participación. Así, David Held (1991:360) sostiene que "no muy por debajo de la superficie del triunfo de la democracia existe una paradoja manifiesta: mientras que se defiende de nuevo la idea del "gobierno del pueblo", la eficacia misma de la democracia como una forma nacional de organización política se ve puesta en duda". Pero, aunque el análisis que sigue a este enunciado es de suma importancia, ya que trata fundamentalmente sobre la interconexión y sistemas mundiales, la superación política de las fronteras estatales y el establecimiento de instituciones decisorias de naturaleza supranacional, en cuanto concierne a los servicios sociales, las críticas a la democracia representativa se ciernen más sobre los factores que obstaculizan una mayor profundización en los aspectos participativos del sistema político. Un ejemplo ilustrativo de esta realidad en nuestro país es el artículo de Manuel Montañés (y otros; 1996:23) en el que denuncia explícitamente que mientras "unos apelamos porque la sociedad civil asuma su protagonismo y sea copartícipe de las decisiones públicas, otros, sin embargo, quieren una sociedad civil domesticada y como servicio complementario para tapar los agujeros que van surgiendo en el proceso de desmantelamiento del Estado de Bienestar".

En mi opinión, este sano inconformismo crítico manifestado contra las instituciones, y no estoy aludiendo al autor, puede correr, no obstante, un riesgo de lamentables tintes "demagógicos", esto es, la ausencia de verdaderas alternativas susceptibles de ser llevadas a la práctica, en otras palabras, "pecar" de excesivo celo al enarbolar la participación ciudadana como un banderín progresista sin presentar, al mismo tiempo, procedimientos y argumentos sólidos que hagan viable, ciertamente, la materialización de estas opciones. En esta línea, Ramón Cotarelo (1990:71) ha expresado que "a veces da incluso la impresión de que quienes insisten en proponer un aumento de la participación, desconocen los cauces reales para llevarla a cabo, con lo cual hacen legítima la duda sobre sus auténticas intenciones. Y, en el peor de los casos, las mencionadas instituciones, como la iniciativa popular, el referéndum, la petición, la revocación, las únicas viables en régimen de compatibilidad con la democracia representativa (ya... que nadie parece reclamar hoy de verdad una democracia directa) también son consideradas como informales e insuficientes por los críticos izquierdistas". 
No obstante, es justo admitir que ciertas medidas están siendo estudiadas seriamente, incluso aplicadas algunas de ellas, en otros Estados muy en consonancia con la noción de "autonomía democrática", introducida por David Held (1991:347), según el cual "la aplicación del principio de autonomía, en torno a un proceso de doble democratización, produce un modelo de Estado y de sociedad civil,... el modelo comprende un número de propuestas que en conjunto podrían crear las condiciones para la defensa y desarrollo de la democracia en las condiciones contemporáneas (en donde) el Estado garantizaría los recursos y los servicios para el cuidado de los niños, las clínicas de salud y los colegios, al tiempo que dejaría el gobierno de esas organizaciones a comunidades locales". Propuestas de esta naturaleza proceden de los gobiernos escandinavos acerca de cómo conseguir una ampliación gradual de la propiedad social productiva, las cuales encuentran su razón de ser, lógicamente, tanto en el desarrollo como en las adversidades que tiene que hacer frente el Estado de Bienestar.

No es de extrañar, pues, como se ha comentado ya desde distintos foros, que los municipios se están convirtiendo, dada la proximidad ciudadano/poder político/asuntos comunitarios, en los laboratorios más afines a estos intentos de cambios democratizadores. Por otro lado, y a mi modo de ver, la corriente alternativa al Estado de Bienestar, conocida bajo la rúbrica de "pluralismo de bienestar", por ejemplo, presenta una oferta peculiar caracterizada por la participación de los usuarios en el proceso de adopción de decisiones en materia de servicios sociales a nivel local, por más que también esta opción plausible introduce serios inconvenientes que indudablemente, sin la adopción previa de garantías necesarias, cuestionarían seriamente su efectividad, tales como, y en opinión de Garcés Ferrer (1996:49), la delimitación de la iniciativa para la gestión de los recursos de servicios sociales (administración pública v.s. iniciativa social) o, más concretamente, y en lo que concierne a nuestro país, la ausencia de a) una autonomía económica y administrativa, b) una conciencia de autogestión de servicios y c) una estructuración del voluntariado, indispensable para lograr este cometido ${ }^{8}$. Interrogantes importantes del tipo de qué legitimidad dis-

A este respecto, a modo de aportación personal, una profunda reestructuración de los Consejos de Servicios Sociales o Bienestar Social, desde los cuales potenciar una mayor partícipación de los grupos sociales en todos los niveles de la administración del Estado, cuyas posibles funciones más determinantes (lejos del mero asesoramiento consultivo presente), amplia representación (no reducida sólo a ciertos colectivos establecidos por el marco jurídico actual) y legitimidad democrática (condición sine que non para participar a un mismo nivel de igualdad con el poder político) permitirían una mayor efectividad y aceptación de la que escasamente gozan hoy día estas instituciones complementarias en el proceso de adopción de decisiones. En definitiva, una vía participativa más acorde con los principios representativos que caracterizan nuestros modelos democráticos actuales. 
pondrían los grupos ciudadanos-copartícipes en el proceso de adopción de decisiones en la esfera local, deben ser resueltas con suma prudencia y reflexión. Quizás, sería más conveniente, a pesar de la aparente paradoja, girar nuevamente hacia la delegación característica del sistema representativo con base electoral para, por ejemplo, componer futuros órganos, abiertos a todos los colectivos de ciudadanos y desde los cuales coparticipar en la gestión de los asuntos comunitarios, en lugar de criticar sin fundamentos ni alternativas verosímiles nuestro presente modelo de organización política que, aunque no es perfecto y difícilmente lograremos uno, dicho sea de paso, se presenta actualmente como el único modelo válido susceptible de exportación universal.

\section{CONCLUSIONES}

La Ciencia Política aspira ser una ciencia más en el seno de las denominadas Ciencias Sociales, para cuyo objetivo se dota de a) un objeto (el poder: su naturaleza, legitimidad, ejercicio e interacciones) que, aunque difícilmente autónomo, sí circunscribe, por el contrario, una esfera específica del comportamiento humano como ser social, y b) un método científico apto para la investigación de su objeto de estudio, desafiando los complejos problemas epistemológicos que retan a nuestra área del saber a la hora de formular enunciados con rango de leyes científicas.

Por su parte, los Servicios Sociales, reconocidos como instrumentos de política social, confluyen con la Ciencia Política en a) los actores protagonistas que detentan el poder y deciden políticamente, b) la participación ciudadana, columna vertebral del sistema democrático desde un punto de vista teórico, c) evolución paralela de los modelos de satisfacción de las necesidades junto a los rasgos específicos que caracterizan la finalidad del Estado en cada momento histórico, d) la naturaleza pública del sistema de servicios sociales que define el modelo de organización política presente, el Estado de Bienestar y e) la necesidad de conocer los otros actores políticos (partidos políticos y administraciones públicas) y agentes sociales (grupos de presión de naturaleza diversa) que intervienen directa e indirectamente en el proceso de adopción de decisiones y de los cuales depende el futuro de la permanencia pública de toda la red de servicios sociales.

Finalmente, las insuficiencias del modelo democrático actualmente exigen medidas reformadoras capaces de hacernos superar los obstáculos que imposibilitan en la actualidad una participación más activa de la ciudadanía. Por esta razón, deben ser bien recibidos los modelos 
alternativos al presente sistema participativo que tan abiertamente está mostrando sus insuficiencias y, como era de esperar, sus desagradables consecuencias manifestadas en la apatía, el desinterés e, incluso, la desidia, que un número cada vez mayor de ciudadanos muestra, en general, hacia todo "lo político" y, más concretamente, hacia la colaboración ciudadana en asuntos de su comunidad. Modelos alternativos como el elaborado por Garcés Ferrer (1997) en su ponencia de GuadixGranada sobre los servicios sociales y las políticas de igualdad, que invita, no sólo a una seria reflexión sobre las insuficiencias tantas veces mencionadas, sino también, y más relevante aún, a expresar este saludable conformismo hacia un sistema, si se me permite, ortopédico, que malentiende lo que debe ser entendido por una participación ágil, activa e ilusionada". Pero las críticas y alternativas hacia nuestro sistema representativo requieren igualmente prudencia, reflexión y desapasionamiento, so pena de caer rápidamente en la mera demagogia propagandística, falsamente progresista y desafortunadamente útil sólo para minar un modelo de organización política que garantiza, como mínimo, el acceso, ejercicio y alternativa en el poder por medios pacíficos. Los sucesos históricos son irrepetibles, pero sus lecciones, que no debemos olvidar, son magistrales.

\section{BIBLIOGRAFÍA}

ALEMÁN BRACHO, M. ${ }^{\circ}$ del C. y GARCÉS FERRER, J. (dir.): Administración Social: servicios de bienestar social. Siglo XXI. Madrid, 1996.

AMÉZAGA, J.: «Democracia y participación» en Revista de Trabajo Social, n. ${ }^{\circ} 133$ (marzo). Ed. Colegio Oficial de Diplomados en Trabajo Social y Asistentes Sociales de Cataluña. 1994.

DE LA RED, N.: «El Trabajo Social en los servicios de bienestar social». Citado por ZAMANILLO, T. «Bienestar y Trabajo Social» en Pros y Contras del Estado de Bienestar, CASILDA, R. y TORTOSA, J.M." (ed.). Tecnos. Madrid, 1996.

EASTON, D.: Esquema para el análisis político. Amorrortu. Buenos Aires, 1969.

GARCÉS FERRER, J.: Sistema político y administrativo de los servicios sociales. Tirant lo Blanch. Valencia, 1996.

" En opinión de Garcés Ferrer (1997), su peculiar modelo de 'empresa social comprometida' es "una nueva forma de organización económica y social capaz de erigirse como instrumento creativo para un nuevo compromiso social e ideológico... que trasciende lo meramente societal así como el modelo de gestión privada de recursos públicos de bienestar, y en su lugar, la sociedad entra a gestionar espacios conflictivos... a los que por razones políticas o económicas el Estado y el mercado ya no pueden dar una respuesta efectiva y se baten en retirada". 
GARCÉS FERRER, J.: «Los servicios sociales y las políticas de igualdad» (ponencia), Guadix-Granada, 14/15 de marzo de 1997.

GARCÍA COTARELO, R.: Introducción a la Teoría del Estado. (comp.) Teide (3. ' ed.). Barcelona, 1986.

GARCÍA COTARELO, R.: Del Estado del Bienestar al Estado del Malestar. Centro de Estudios Constitucionales. Madrid, 1986.

GARCÍA COTARELO, R.: Crítica a la Teoría de Sistemas. C.I.S., 1979.

GARCÍA COTARELO, R.: En torno a la Teoría de la Democracia. Cuadernos y Debates 23. Centro de Estudios Constitucionales. Madrid, 1990.

GARCÍA HERRERO, G. y RAMÍREZ NAVARRO, J.M.: Los nuevos servicios sociales. (2. ${ }^{a}$ ed.) Certeza. Zaragoza, 1992.

GINER, S.: Sociología. (nueva ed. revisada). Península. Barcelona, 1996.

HARO TECGLEN, E.: Diccionario Político. Planeta. Barcelona, 1995.

HELD, D.: Modelos de democracia. Alianza Universidad. Madrid, 1991.

MONTAÑÉS, M. (y otros): «¿Asociaciones de voluntarios?. Lo que se dice y lo que se quiere decir cuando hablamos de voluntariado», en Voluntariado, Documentación Social. Cáritas Española, n. ${ }^{\circ}$ 104, julio/septiembre, 1996. PÉREZ ROYO, J.: Introducción a la Teoría del Estado. Blume. Barcelona, 1980.

SABINE, G.: Historia de la Teoría Politica. Fondo de Cultura Económica. (16. ${ }^{2}$ reed.). México, 1987.

SARTORI, G.: La Política, lógica y método en las Ciencias Sociales. Fondo de Cultura Económica. México, 1984.

SMITH, A.: Teoría de los sentimientos morales. Fondo de Cultura Económica. México, 1978. 